\title{
Septic Pulmonary Emboli Secondary to Pyogenic Liver Abscess in a Diabetic Patient
}

\author{
Takahiro Zenda, Ichiro Araki, Yoshio Hiraiwa, Shiro Miyayama*, \\ Takaharu MasunagA**, Yasuo TAKedA**, Toshio Ueno** and Ryoyu TAKedA**
}

\begin{abstract}
A 70-year-old woman with poorly controlled diabetes mellitus was admitted because of persistent remittent fever. Soon a liver abscess was detected as the cause of the fever by ultrasonography, and antibiotic therapy was started. However, suddenly serious dyspnea with chest and back pain developed. The morbid condition was definitely diagnosed as septic pulmonary emboli (SPE) with pulmonary perfusion scan. It should be recognized that liver abscess can be a latent focus of systemic metastatic complications such as SPE, and not only early detection but also prompt appropriate drainage of liver abscesses is essential.
\end{abstract}

(Internal Medicine 34: 42-45, 1995)

Key words: septic metastatic complication, Klebsiella pneumoniae, ultrasonography

\section{Introduction}

Liver abscess is a serious complication of diabetes mellitus (DM). The association of DM with liver abscess, especially solitary ones, has been reported by many investigators $(1-4)$. However, few reports have focused on the metastatic lesions of liver abscess (5-6). Here, we describe a rare case of septic pulmonary emboli (SPE) secondary to liver abscess which developed against a background of poor diabetic control.

\section{Case Report}

A 70-year-old Japanese woman was admitted to our hospital with a two-week history of general malaise and intermittent fever of $39^{\circ} \mathrm{C}$ in September 1989. She had been already diagnosed as having non-insulin-dependent DM in 1977, and treated with an oral agent until this admission by another local physician. She had no other remarkable medical history, but her sister also suffered from DM. On admission, she was febrile $\left(38.8^{\circ} \mathrm{C}\right)$, and no findings were noted except for relatively poor nutrition and dehydration on physical examination. As shown in Table 1, the laboratory examination revealed leukocytosis with neutrophil dominance, elevation of the erythrocyte sedimentation rate and $\mathrm{C}$-reactive protein. Elevation of blood sugar and hemoglobin $\mathrm{A}_{1 \mathrm{c}}$ indicated poor control of her DM. Hypoalbuminemia, lowered cholinesterase, elevation of bile duct enzymes and mild elevation of transaminase were also observed. Urine gave a strong positive test for glucose and ketone bodies. Klebsiella pneumoniae was isolated in blood culture. Abdominal ultrasonic examination disclosed an oval hypoechoic space occupying lesion (approximately $4.5 \times 3.5 \mathrm{~cm}$ in diameter) situated in

Table 1. Laboratory Data on Admission

\begin{tabular}{|c|c|c|c|}
\hline \multicolumn{2}{|l|}{ Urinalysis } & \multicolumn{2}{|c|}{ Lactate dehydrogenase $545 \mathrm{IU} / 1$} \\
\hline Protein & $(-)$ & Total bilirubin & $0.6 \mathrm{mg} / \mathrm{dl}$ \\
\hline Sugar & $(4+)$ & Total protein & $4.9 \mathrm{~g} / \mathrm{dl}$ \\
\hline Ketone body & $(3+)$ & Albumin & $2.6 \mathrm{~g} / \mathrm{dl}$ \\
\hline Occult blood & $(+/-)$ & Cholinesterase & $0.53 \Delta \mathrm{pH}$ \\
\hline Blood cell count & & Total cholesterol & $103 \mathrm{mg} / \mathrm{dl}$ \\
\hline White blood cell & $17,900 / \mathrm{mm}^{3}$ & Triglyceride & $64 \mathrm{mg} / \mathrm{dl}$ \\
\hline Stab & $18 \%$ & Blood sugar & $319 \mathrm{mg} / \mathrm{dl}$ \\
\hline Segmented & $75 \%$ & HbAlc & $11.3 \%$ \\
\hline Lymphocyte & $4 \%$ & Blood urea nitrogen & $31 \mathrm{mg} / \mathrm{dl}$ \\
\hline Monocyte & $3 \%$ & Creatinine & $0.4 \mathrm{mg} / \mathrm{dl}$ \\
\hline Red blood cell & $374 \times 10^{4} / \mathrm{mm}^{3}$ & \multicolumn{2}{|l|}{ Serology } \\
\hline Hemoglobin & $11.2 \mathrm{~g} / \mathrm{dl}$ & \multicolumn{2}{|c|}{ Erythrocyte sedimentation rate } \\
\hline Hematocrit & $35.1 \%$ & \multicolumn{2}{|r|}{$67 \mathrm{~mm} / \mathrm{h}$} \\
\hline Platelet & $22.9 \times 10^{4} / \mathrm{mm}^{3}$ & $\begin{array}{l}\text { C-reactive protein } \\
\alpha \text { fetoprotein }\end{array}$ & $\begin{array}{r}17.8 \mathrm{mg} / \mathrm{dl} \\
4.3 \mathrm{ng} / \mathrm{ml}\end{array}$ \\
\hline \multicolumn{2}{|l|}{ Blood chemistry } & \multicolumn{2}{|c|}{ Blood gas analysis (room air) } \\
\hline & \multicolumn{2}{|r|}{7.502} \\
\hline \multicolumn{2}{|c|}{ Alanine aminotransferase $\quad 66 \mathrm{IU} / 1$} & $\mathrm{PaO}_{2}$ & $6.6 \mathrm{mmHg}$ \\
\hline \multicolumn{2}{|c|}{ Alkaline phosphatase } & $\mathrm{PaCO}_{2}$ & $4.3 \mathrm{mmHg}$ \\
\hline \multicolumn{2}{|c|}{$\gamma$-Glutamyl transpeptidase $143 \mathrm{IU} / \mathrm{l}$} & $\mathrm{O}_{2}$ Saturation & $86.5 \%$ \\
\hline
\end{tabular}

From the Departments of Internal Medicine and *Radiology, Toyama Red Cross Hospital, Toyama, **the Second Department of Internal Medicine, School of Medicine, University of Kanazawa, Kanazawa

Received for publication April 18, 1994; Accepted for publication September 19, 1994

Reprint requests should be addressed to Dr. Takahiro Zenda, the Second Department of Internal Medicine, University of Kanazawa, Takara-machi 13-1 Kanazawa, Ishikawa 920 
the lower posterior segment of the right hepatic lobe (Fig. 1A), Computed tomography (CT) showed a low density area, which was enhanced circularly with a clear margin and several septa (Fig. 1B). Since these findings were compatible with pyogenic liver abscess, antibiotic therapy with cefoperazone sodium (CPZ) was initiated, and additionally percutaneous abscess drainage was scheduled. However, she immediately complained of severe dyspnea with chest and back pain. The arterial blood gas analysis while breathing room air showed severe hypoxia $\left(\mathrm{PaO}_{2} 46.6 \mathrm{mmHg}, \mathrm{PaCO}_{2} 34.5 \mathrm{mmHg}, \mathrm{O}_{2}\right.$ saturation $86.5 \%$ ). Chest roentgenogram revealed equivocal scattered nodular shadows in the bilateral lung fields with a small amount of pleural effusion. One of the pulmonary nodules looked like a thin-walled cystic lesion (Fig. 2). Chest CT also revealed multiple nodular lesions of various sizes scattered in the bilateral lung fields. Some of the nodules were surrounded with consolidation, and contained cavities (Fig. 3). Pulmonary perfusion scan with ${ }^{99 \mathrm{~m}} \mathrm{Tc}$-macroaggregated albumin revealed multiple perfusion defects consistent with nodular lesions (Fig.
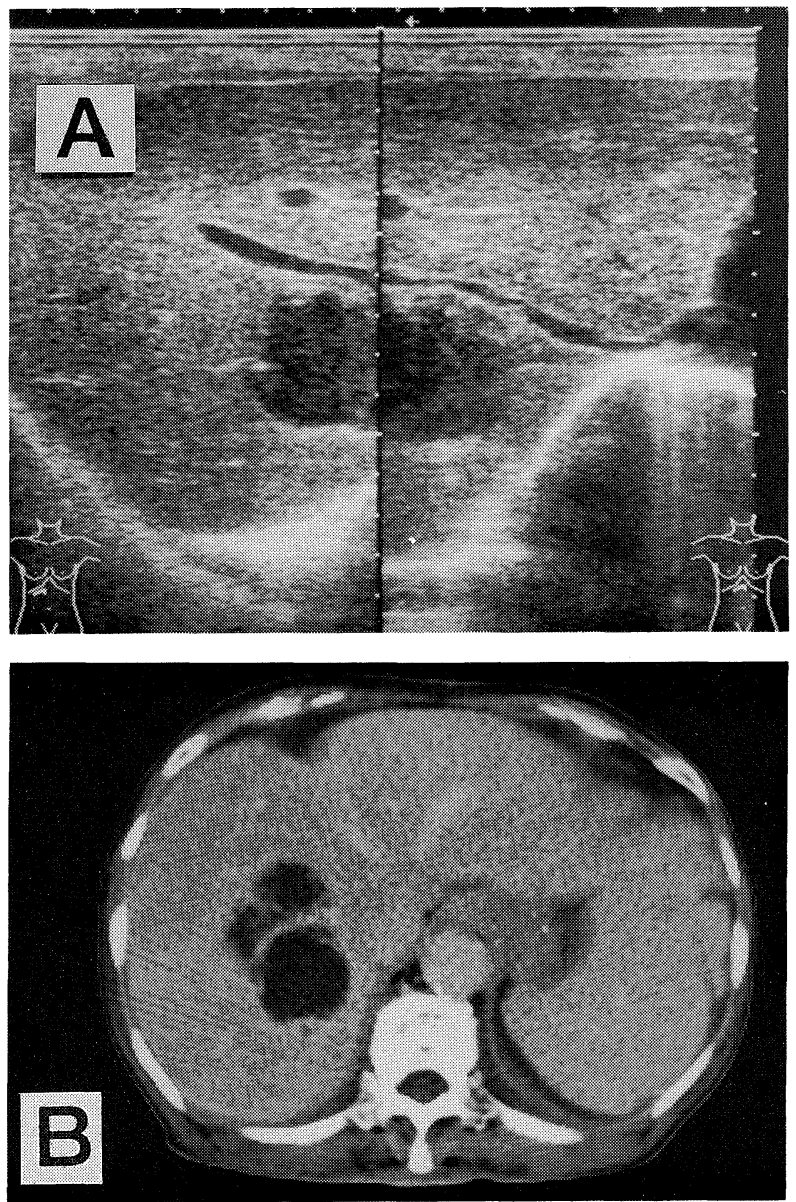

Fig. 1. A) Ultrasonography reveals an oval hypoechoic lesion with an irregular margin and uneven internal echo, situated in the posterior segment of the right hepatic lobe. B) Computed tomography reveals an oval low density area with marginal enhancement in the right hepatic lobe.

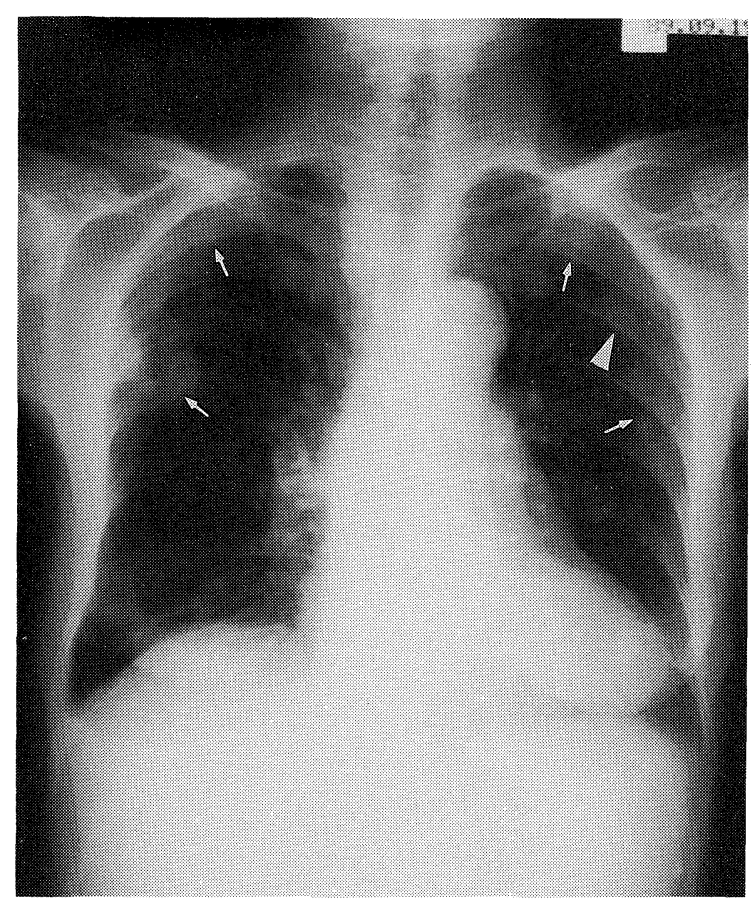

Fig. 2. Chest roentgenogram reveals scattered equivocal patchy shadows (arrows) in the bilateral lung fields, some of which contain thin-walled cystic area (arrowhead).

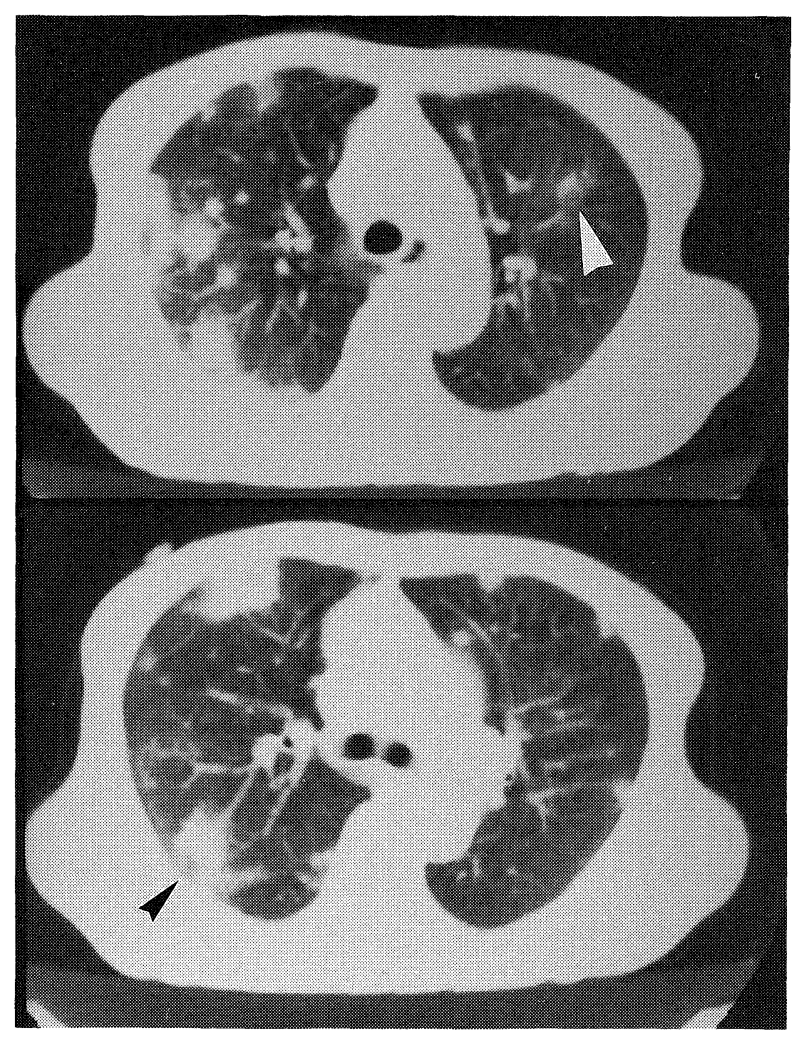

Fig. 3. Chest computed tomography reveals multiple nodular lesions, prominently scattered in the bilateral peripheral lung fields. Some of the nodules were surrounded by consolidation, and formed cavitation (arrowheads). 
4). Since these findings were highly suggestive of SPE originating from a liver abscess, drainage with a percutaneous transhepatic catheter was performed immediately under ultrasonography (US) guidance. Klebsiella pneumoniae, which was sensitive to piperacillin sodium (PIPC), gentamicin sulfate (GM) and CPZ, was also isolated from the culture of purulent aspirates. Furthermore, respiratory support with nasal intubation, intensive antibiotic therapy with PIPC, CPZ and isepamicin sulfate, lavage of the abscess with GM solution, and strict control of blood sugar with continuous subcutaneous insulin infusion were also achieved. The small nodular shadows fused gradually and showed consolidation with increased pleural effusion (Fig. 5). The respiratory failure and fever ameliorated gradually, and she recovered completely. The funduscopic

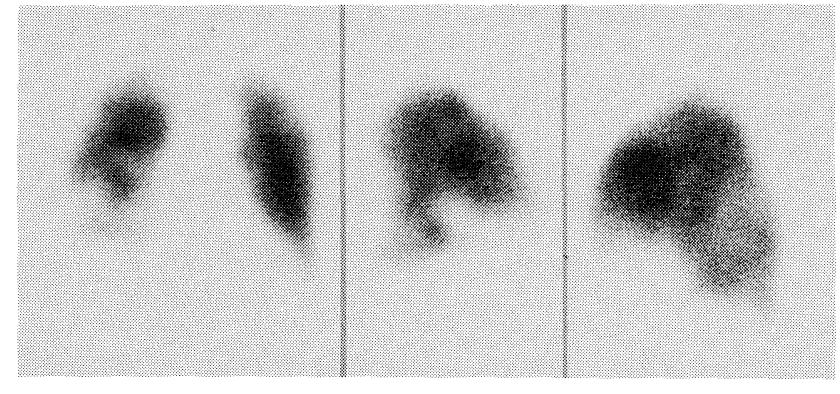

Fig. 4. ${ }^{99 \mathrm{~m}} \mathrm{Tc}-\mathrm{MAA}$ pulmonary perfusion scan reveals multiple perfusion defects. MAA, macroaggregated albumin.

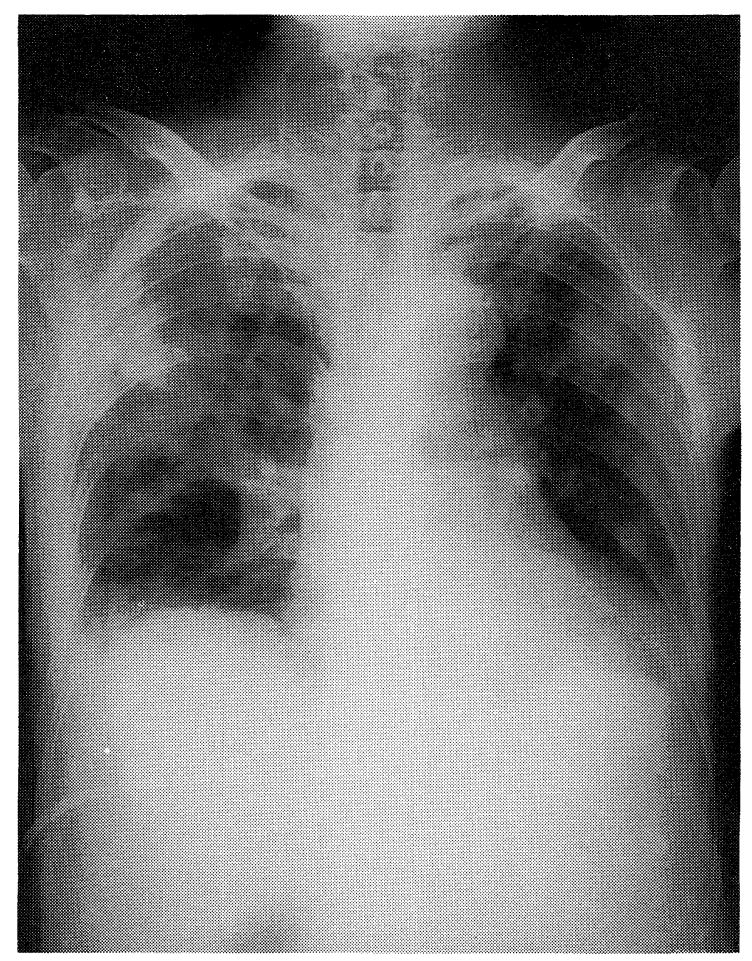

Fig. 5. The nodular shadows fused gradually and showed consolidation with increased pleural effusion. examination revealed diabetic changes of Scott's grade II, but no evidence of septic metastatic lesions.

\section{Discussion}

Pyogenic liver abscess is an uncommon but serious complication of DM. The possible association between solitary pyogenic liver abscess and DM has been often discussed (1-4). However, not much attention has been paid to the metastatic lesions of liver abscess, although septic metastatic endophthalmitis, which often results in serious visual disturbance, has been occasionally reported in the literature $(5,6)$. In addition to endophthalmitis, pulmonary abscess, cerebral abscess, purulent meningitis, otitis media, osteomyelitis, arthritis, prostatic abscess and psoas abscess have also been reported as metastatic complications of pyogenic liver abscess $(2,4,5)$. But, to our knowledge, there are no other documented cases of SPE, which originated from pyogenic liver abscess and developed into serious acute respiratory failure. Therefore, the present case is rare and significant in that it suggests that untreated liver abscess can be a latent focus of systemic septic metastasis.

SPE is a rare morbid condition characterized by pulmonary infarction and/or emboli, and secondary pulmonary infection caused by clot, fibrin matrix and other particles which are contaminated with micro-organisms (7). Various sources, such as right-sided endocarditis, intravenous drug abuse, suppurative phlebitis, pelvic thrombophlebitis, prolonged indwelling catheters, arteriovenous shunt for hemodialysis, suppurative process of neck or head soft tissue and gangrene of extremity have been reported (7-9). While drug addiction is the most common cause of SPE in the United States (7-9), the diabetic milieu also has a possible promotive role in SPE, in that hematogenous metastasis may be facilitated by the intimal vascular abnormality (4). Furthermore, we suppose that the hypercoagulability of peripheral blood caused by hyperglycemia (8), aggravation of thrombocytic adhesion or coagulation, diminished erythrocytic deforming faculty, increased procoagulant protein and decreased fibrinolytic function (10) may also exert a harmful influence on the pulmonary embolism.

Since the fatal or poor outcome is mainly attributed to delayed diagnosis of liver abscess or $\operatorname{SPE}(1,3,5)$, early diagnosis and treatment are essential $(4,7,8)$. The initial diagnosis of SPE is often difficult (9), because plain roentgenography shows a non-specific equivocal infiltrate, like patchy or nodular bronchopneumonia $(7,9,11)$. However, it has been reported that approximately $10 \%$ of patients revealed the target sign on plain roentgenography, which signifies a suspended nodular density of thin-walled hyperlucent cavity, as a specific picture (12). Similarly the complemental utility of $\mathrm{CT}$ in the diagnosis of SPE is advocated. Namely, CT is more sensitive than plain roentgenography in detecting pulmonary nodular lesions (9), and scattered peripheral nodules with cavity or distinct feeding vessels are also reported as specific findings of SPE $(9,11)$. In the present case, cystic nodular lesions on plain roentgenography and peripheral nodules with cavitation on CT were observed. Though the diagnosis should 
be confirmed with pulmonary perfusion scan or angiography, considerable attention must be directed to these signs. The therapeutical mainstay of SPE should be the correction of the underlying septic focus, from which large amounts of contaminated embolic substance are expelled into the bloodstream, in addition to respiratory support, intensive antibiotic therapy and heparinization are also used depending on individual circumstance (7). In the present case, we believe that the rapid evacuation of pus diminished the amount of embolic substance and consequently brought about the favourable result. In parallel, strict diabetic control is also a requisite, because hyperglycemia increases the susceptibility to infection by impairing the polymorphonuclear leukocyte functions, such as chemotaxis, phagocytosis and bactericidal action $(2,4,8,13$, 14).

In conclusion, we described an extremely rare SPE case with serious respiratory failure, originating from a liver abscess in a poorly controlled diabetic patient. This case suggested that when a diabetic patient with fever of unknown origin is encountered, the early diagnosis or therapeutic approach to the infection site, and the avoidance of inadequate iatrogenic infection focus are indispensable, in addition to diabetic control. Furthermore, it should be noted that liver abscess can be a latent focus of various systemic metastatic lesions such as SPE.

\section{References}

1) Chew SK, Lim HS, Mah PK, et al. Pyogenic hepatic abscess and diabetes mellitus. A probable association. Ann Acad Med Singapore 14: 261, 1985.

2) Barton EN, Daisley H, Gilbert DT, et al. Diabetes mellitus and Klebsiella pneumoniae liver abscess in adults. Trop Geogr Med 43: 100, 1991.

3) Pitt HA, Zuidema GD. Factors influencing mortality in the treatment of pyogenic hepatic abscess. Surg Gynecol Obstet 140: 228, 1975.

4) Cheng DL, Liu YC, Yen MY, et al. Septic metastatic lesions of pyogenic liver abscess. Their association with Klebsiella pneumoniae bacteremia in diabetic patients. Arch Intern Med 151: 1557, 1991.

5) Liu YC, Cheng DL, Lin CL. Klebsiella pneumoniae liver abscess associated with septic endophthalmitis. Arch Intern Med 146: 1913, 1986.

6) Liao HR, Lee HW, Leu HS. Endogenous Klebsiella pneumoniae endophthalmitis in diabetic patients. Can J Ophthalmol 27: 143, 1992.

7) Gary LG, Kimball IM, Charles RS. Septic pulmonary embolization. Surg Gynecol Obstet 144: 105, 1977.

8) Machimura H, Kaneshige H, Tamura $S$, et al. Two cases of diabetes mellitus with septic pulmonary embolism. Saishin Igaku 44: 385, 1989 (Abstract in English).

9) Kuhlman JE, Fishman EK, Teigen C. Pulmonary septic emboli: Diagnosis with CT. Radiology 174: 211, 1990.

10) Akimitsu T, Okeda $T$, Horita $M$, et al. Cases of giant pyogenic liver abscess accompanying NIDDM. J Japan Diab Soc 36: 405, 1993 (Abstract in English).

11) Huang RM, Naidich DP, Lubat E, et al. Septic pulmonary emboli: CT radiographic correlation. Am J Roentgenol 153: 41, 1989.

12) Zelefsky MN, Lutzker LG. The target sign: A new radiologic sign of septic pulmonary emboli. Am J Roentgenol 129: 453, 1977.

13) Cooppan R. Infection and diabetes. in: Joslin's Diabetes Mellitus. 12th ed. Marble A, Krall LP, Bradley RF, Christlieb AR, Soeldner JS, Eds. Lea \& Febiger, Philadelphia, 1985, p. 737.

14) Bagdade JD, Root RK, Bulger RJ. Impaired leukocyte function in patients with poorly controlled diabetes. Diabetes 23: 9, 1974. 